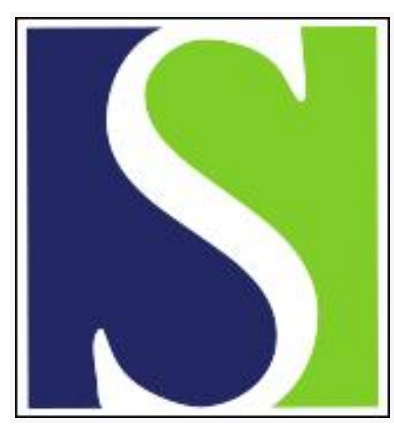

Scand J Work Environ Health 1998;24(5):358-366

https://doi.org/10.5271/sjweh.356

Issue date: Oct 1998

\title{
Lumbar disc degeneration in relation to occupation
}

by Luoma K, Riihimäki H, Raininko R, Luukkonen R, Lamminen A, Viikari-juntura $\mathrm{E}$

The following articles refer to this text: 2001;27(5):346-352; 2012;38(6):577-581

Key terms: accident; car driving; intervertebral disc pathology; lumbar disc; lumbar disc degeneration; lumbar spine; magnetic resonance imaging; MRl; occupation; occupational load; physical load; work-related risk factor

This article in PubMed: www.ncbi.nlm.nih.gov/pubmed/9869307

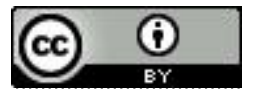




\title{
Lumbar disc degeneration in relation to occupation
}

\author{
by Katariina Luoma, MD, ${ }^{1}$ Hilkka Riihimäki, DMedSci, ${ }^{1}$ Raili Raininko, DMedSci, ${ }^{2}$ Ritva Luukkonen, \\ DSocSci, ${ }^{1}$ Antti Lamminen, DMedSci, ${ }^{3}$ Eira Viikari-Juntura, DMedSci ${ }^{1}$
}

Luoma K, Riihimäki H, Raininko R, Luukkonen R, Lamminen A, Viikari-Juntura E. Lumbar disc degeneration in relation to occupation. Scand J Work Environ Health 1998;24(5):358-366.

\begin{abstract}
Objectives The aim was to study risk factors of lumbar disc degeneration demonstrable with magnetic resonance imaging (MRI) with special emphasis on occupational load and back accidents.

Methods The subjects in this cross-sectional study were 53 machine drivers, 51 construction carpenters, and 60 municipal office workers aged $40-45$ years. Data on possible risk factors were available from current structured questionnaires and for 4 and 7 years in retrospect. The prevalence of lumbar disc degeneration L2/L3-L5/S1 was determined with MRI.

Results An increased risk was found for posterior disc bulges among the carpenters and for anterior disc bulges among the machine drivers, but decreased signal intensity was not related to occupation. Car driving was also associated with anterior disc bulges. All signs of disc degeneration were related to a history of back accidents. Disc degeneration was not related to body height, overweight, smoking, or the frequency of physical exercise.

Conclusions Occupational load affects the risk of disc degeneration of the lumbar spine. Accidental back injuries and motor vehicle driving are associated with an increased risk of disc degeneration. Anterior and posterior disc bulges seem to be related to different types of physical loads.
\end{abstract}

Key terms accidents, car driving, intervertebral disc pathology, lumbar spine, magnetic resonance imaging, physical load, occupational load, work-related risk factors.

Most of the knowledge on the risk factors of disc degeneration is based on X-ray studies, but an increasing number of magnetic resonance imaging (MRI) studies has been performed. Back accidents $(1-3)$, recurrent minor trauma (4), heavy manual materials-handling and postural loading (2), heavy physical exercise (5), whole-body vibration (6), sedentary work (7), car driving (3), smoking (8-9), overweight $(10-11)$, and genetic factors (12) have been proposed as risk factors for disc degeneration. Many X-ray studies have indicated that work-related physical stress is associated with an increased risk of disc degeneration $(2,13-15)$, but in other studies no or only a weak association has been found $(12,16)$. Genetic or familial factors seem to be the most important determinant of disc degeneration (12), but the effect of physical loading combined with individual predisposition is not known. Although the association between heavy labor and disc degeneration has been shown in many studies, the nature of the stress responsible for the degenerative changes is unclear, and it is not known whether the pattern of occurrence of different degenerative disc changes is affected by the type of load imposed on the back.

With a plain X-ray examination only advanced stages of disc degeneration can be seen, but, with MRI, biochemical and morphological changes of the disc can be evaluated and early degenerative changes of the disc can be detected (17-21). The signal intensity of the intervertebral disc is correlated with its water and proteoglycan content (19) and with the density of the collagen fibers of the annulus fibrosus (20). An association between disc bulge and radial fissure of the annulus fibrosus has been found in a cadaver study (22) and in a comparative study with MRI and discography (23). Radial fissure is considered a criterion for degeneration of the disc.

Reprint requests to: Dr Katariina Luoma, Finnish Institute of Occupational Health, Topeliuksenkatu 41 a A, FIN-00250 Helsinki, Finland. [E-mail: kluoma@dlc.fi] 
The objective of this study was to determine the risk factors of lumbar disc degeneration demonstrable with MRI, with special emphasis on occupational load and back accidents.

\section{Subjects and methods}

\section{Subjects}

The subjects in this study comprised a subgroup of 1832 men (688 machine drivers, 533 carpenters, and 591 office workers) who had taken part in 2 repeated questionnaire studies concerning occupational effects on lowback pain (2). Seventy men of each occupational group were selected using age ( $40-45$ years) and place of residence as inclusion criteria; 164 men (71\%) participated in this study. The load imposed on the back at work was distinctly different in each group. Fifty-three of the men were exposed to whole-body vibration and prolonged sitting (machine drivers, longshoremen driving mainly forklift trucks, and ground construction workers driving earthmovers, excavators and other heavy machines), 51 to dynamic physical work (construction carpenters), and 60 to sedentary work (municipal office workers). Machine drivers are occasionally exposed to manual materials-handling, mainly in maintenance work. The work of a carpenter involves manual materials-handling, nonneutral trunk postures, walking on rough surfaces with obstacles, and high accident risk. The office workers' tasks are mainly sedentary, but these workers have the freedom to change posture and move around.

\section{Questionnaire and interview}

A self-administered questionnaire, similar to previous ones, was sent to each subject before the MRI examination. The questionnaire included items on individual characteristics (anthropometric measures and level of education), occupational history (seniority and exposures at work), life-style (annual car driving, weekly physical exercise, smoking), and history of low-back problems. On the day of the MRI examination the questionnaire was checked for the completeness of answers by a nurse, who furthermore performed a structured interview to obtain some additional and more-detailed information.

Job title was used as the measure of occupational load. Each occupation has a distinctly different exposure profile. No objective assessment of exposure was done. A detailed description of the number of years in different types of work (sedentary work, static standing work, variable light work, work involving machine operating or car driving, light physical work, and heavy physical work) was obtained in the interview. Only a few men had worked for several years in jobs that differed from their current types of jobs. When the job title was substituted in the analyses with the more-detailed information about the number of years in different types of work, the results were essentially the same. Therefore job title was kept as the indicator of work load.

The workers' history of accidental back injuries was asked with the following questions: "Have you had back accidents due to which you have been on sick leave for at least 2 weeks? If yes, how many times? What kind of injuries were caused by the accidents? [strain, fracture, contusion, other (specify)]. A 3-class variable was formed for the history of back accidents $(0,1$ to 2 , and $\geq 3$ back accidents). Based on self-reports given in the questionnaire on body weight and height currently and at the age of 25 years, a history of overweight was constructed and classified into the 3 classes of no overweight [body mass index $(\mathrm{BMI})<24 \mathrm{~kg} / \mathrm{m}$ (2) at both ages], overweight [BMI $\geq 27 \mathrm{~kg} / \mathrm{m}$ (2) at both ages], and other (an intermediate class). Height was classified as $<175,175-179$, and $\geq 180 \mathrm{~cm}$. Smoking was classified into the 3 classes of no smoking ever (nonsmokers), smoking in the past (ex-smokers), and current smoking (smokers). The history of leisure-time physical exercise given in each of the 3 questionnaires was classified into the 3 classes of physical exercise $\leq 1$ time a week at all time points (infrequent exercise), constantly $>2$ times a week (frequent exercise), and an intermediate class. The history of car driving was classified into the 2 classes of much car driving (driving at least $15000 \mathrm{~km} /$ year at each of the time points) and less car driving (other). A description of the variables is presented in table 1.

\section{Examination by magnetic resonance imaging}

The subjects underwent MRI of the lumbar spine in the sagittal plane with an $0.1 \mathrm{~T}$ imager and a surface coil using a dual echo technique (DE 2000/25-86) with 2 acquisitions. The slice thickness was $7 \mathrm{~mm}$, the field of view $410 \times 410 \mathrm{~mm}$, and the pixel size $1.6 \mathrm{~mm}$.

All the examinations were included in the study even though the general image quality was deemed to be poor in 16 cases $(9.8 \%)$. The image quality was not sufficient for a reliable evaluation of the discs at $\mathrm{L} 1 / \mathrm{L} 2$ or some discs at other levels, most of them at L5/S1, and these observations were recorded as missing.

\section{Classification of disc degeneration}

A decreased signal intensity of the nucleus pulposus on $\mathrm{T} 2$-weighted images and disc bulges on proton density images were used as signs of disc degeneration (figure 1).

Signal intensity of the nucleus pulposus of intervertebral discs L2/L3-L5/S1 was visually estimated independently by 3 radiologists using the cerebrospinal fluid (CSF) at the corresponding disc level as an intensity reference (24-25). Intensity lower than that of the adjacent CSF was considered a positive finding and was 
called dark nucleus pulposus. The data of the most experienced radiologist were used for the data analysis. The interobserver agreement (weighted kappa) between each pair of radiologists ranged from 0.59 to 0.83 at various disc levels $(\mathrm{N}=164)$. The intraobserver agreement rate was $57-81 \%$ for various disc levels $(\mathrm{N}=22)$. [Because of the small number of double assessments, the kappa coefficient was not calculated.]
The magnitude of the anterior and posterior disc bulges was measured by one of the radiologists in the middle sagittal line of the disc with the facility of the MRI device (figure 2 ). A bulge reaching $\geq 3.2 \mathrm{~mm}$ beyond the outer edges of 2 adjacent vertebrae was considered a sign of degeneration. The intraobserver agreement rate was $81-92 \%$ for the posterior bulges and $86-100 \%$ for the anterior bulges at different disc levels $(\mathrm{N}=25)$.

Table 1. Work history, previous back accidents, individual characteristics, and life-style factors of the occupational groups.

\begin{tabular}{|c|c|c|c|c|c|c|c|c|c|c|c|c|c|c|c|c|}
\hline \multirow{2}{*}{$\begin{array}{l}\text { Occu- } \\
\text { pa- } \\
\text { tional } \\
\text { group }\end{array}$} & \multirow{2}{*}{$\begin{array}{l}\text { Duration } \\
\text { of occu- } \\
\text { pation } \\
\text { (years) }\end{array}$} & \multicolumn{2}{|c|}{$\begin{array}{c}\text { History } \\
\text { of back } \\
\text { accidents }\{\%\}\end{array}$} & $\begin{array}{c}\text { History } \\
\text { of car } \\
\text { driving }(\%)\end{array}$ & \multicolumn{3}{|c|}{$\begin{array}{c}\text { History } \\
\text { of physical } \\
\text { exercise (\%) }\end{array}$} & \multicolumn{3}{|c|}{$\begin{array}{c}\text { Smoking } \\
(\%)\end{array}$} & \multicolumn{3}{|c|}{$\begin{array}{l}\text { Height } \\
(\%)\end{array}$} & \multicolumn{3}{|c|}{$\begin{array}{c}\text { History } \\
\text { of overweight }\end{array}$} \\
\hline & & 0 & $1-2 \geq 3$ & $\begin{array}{ll}<15000 & \geq 15000 \\
\mathrm{~km} / \text { year } & \mathrm{km} / \text { year }\end{array}$ & $\begin{array}{l}\text { In- } \\
\text { frequent } \\
\text { exercise }\end{array}$ & $\begin{array}{c}\text { Other } \\
\text { exercise }\end{array}$ & $\begin{array}{l}\text { Frequent } \\
\text { exercise }\end{array}$ & $\begin{array}{l}\text { Non- } \\
\text { smoker }\end{array}$ & $\begin{array}{l}\text { Ex- } \\
\text { smoker }\end{array}$ & $\begin{array}{l}\text { Current } \\
\text { smoker }\end{array}$ & $\begin{array}{l}<175 \\
\mathrm{~cm}\end{array}$ & $\begin{array}{c}175- \\
179 \mathrm{~cm}\end{array}$ & $\begin{array}{c}\geq 180 \\
\mathrm{~cm}\end{array}$ & $\begin{array}{l}\text { No } \\
\text { over- } \\
\text { weight }\end{array}$ & Other & $\begin{array}{l}\text { Over- } \\
\text { weight }\end{array}$ \\
\hline
\end{tabular}

\begin{tabular}{|c|c|c|c|c|c|c|c|c|c|c|c|c|c|c|c|c|c|c|}
\hline $\begin{array}{l}\text { Machine } \\
\text { drivers } \\
(\mathrm{N}=53)\end{array}$ & 26.1 & 52.8 & 34.0 & 13.2 & 64.2 & 35.9 & 18.9 & 54.7 & 26.4 & 26.4 & 41.5 & 41.5 & 24.5 & 26.4 & 49.1 & 13.2 & 56.6 & 30.2 \\
\hline $\begin{array}{l}\text { Carpenters } \\
(\mathrm{N}=51)\end{array}$ & 26.3 & 49.0 & 29.4 & 21.6 & 56.9 & 43.1 & 35.3 & 49.0 & 15.7 & 15.7 & 31.3 & 39.6 & 33.3 & 37.3 & 29.4 & 15.7 & 66.7 & 17.7 \\
\hline $\begin{array}{l}\text { Office } \\
\text { workers } \\
(\mathrm{N}=60)\end{array}$ & 26.1 & 83.3 & 13.3 & 3.3 & 85.0 & 15.0 & 26.7 & 41.7 & 31.7 & 31.7 & 26.7 & 26.7 & 30.0 & 33.3 & 36.7 & 33.3 & 55.0 & 11.7 \\
\hline
\end{tabular}
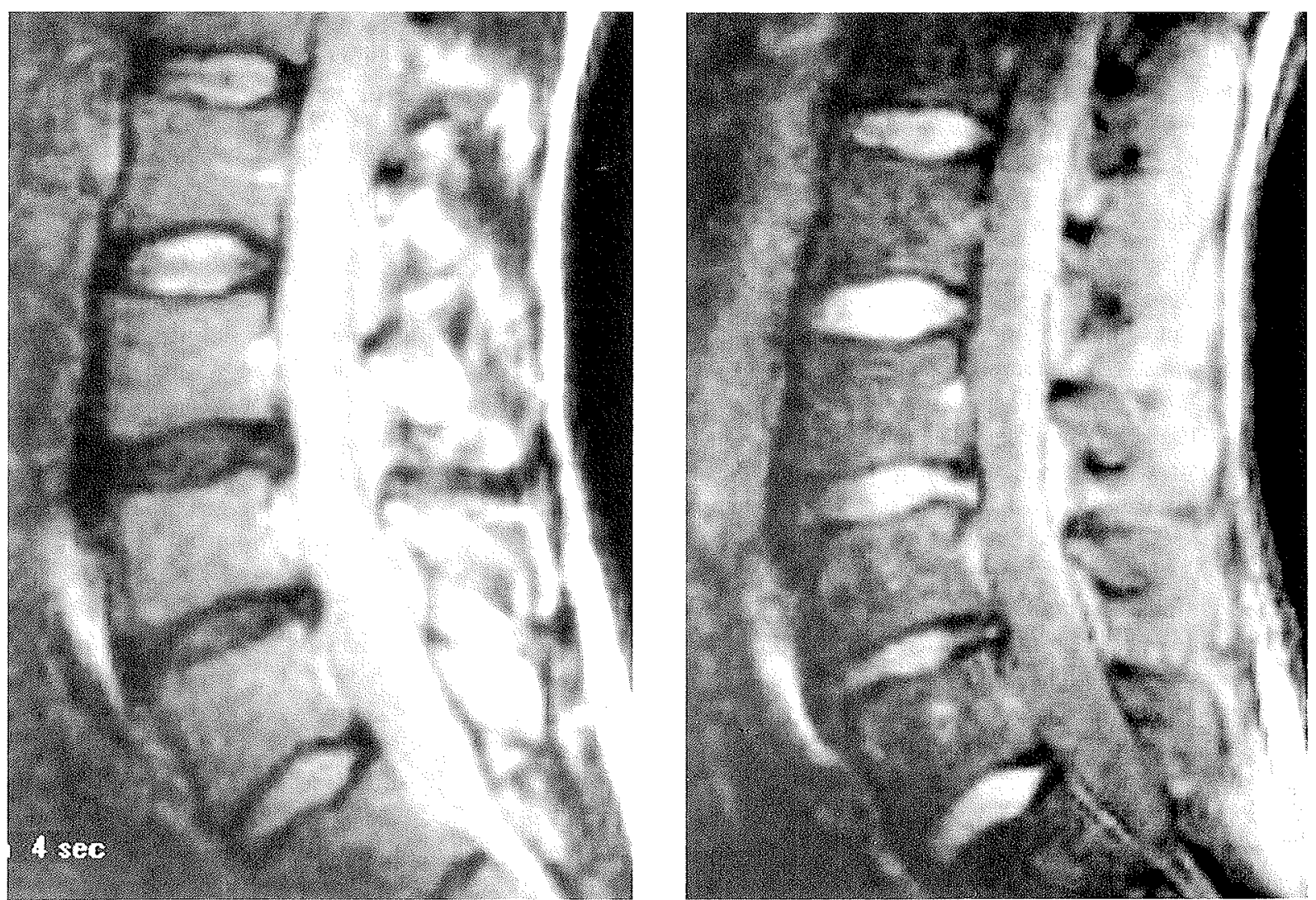

Figure 1. Decreased signal intensity of the nucleus pulposus in discs $L 3 / L 4$ and $L 4 / L 5$ in the T2-weighted image (a). The anterior and posterior bulges in these discs were more clearly demonstrated in the proton density-weighted image (b). 


\section{Statistical analysis}

The association of the signs of disc degeneration with job title, history of back accidents, and other possible risk factors was analyzed using logit models and logistic regression models. The dependent variables were dark nucleus pulposus, posterior bulge, and anterior bulge of discs L3/L4, L4/L5, and L5/S1. The potential risk factors were occupation and history of back accidents, whereas height, history of overweight, smoking, physical exercise, and car driving were considered confounders. The number of positive findings for disc L2/L3 was too low for reliable analysis.

The association between the potential risk factors and the signs of disc degeneration of the lumbar spine was first analyzed using the findings for discs L3/L4-L5/S1 as the dependent variables. This procedure is called the overall analysis later in the text. The logit model for repeated binary response (26) was used and the chi-square test was calculated to assess the associations with the 3 dependent variables. The number of findings was limited, and therefore only 1 independent variable at a time was used in the logit models.

The effect of occupation and the history of back accidents on the signs of disc degeneration were further analyzed with logistic regression models taking into account the potential confounding by other explanatory variables. Dependent variables were dark nucleus pulposus and anterior and posterior disc bulge of discs L3/L4, L4/ L5 and L5/S1. Odds ratios (OR) and their 95\% confidence intervals $(95 \% \mathrm{CI})$ were calculated.

\section{Results}

\section{Dark nucleus pulposus}

The prevalence of dark nucleus pulposus increased in the caudal direction in each occupational group (figure 3 ). In the overall analysis of the lumbar spine, there was a significant association between the dark nucleus pulposus and the number of back accidents $\left(\chi^{2}\right.$ test, $\left.P=0.02\right)$. No statistically significant associations were found between dark nuclei pulposi and occupation.

In the disc-level-specific analyses dark nucleus pulposus was not significantly related to occupation (table 2 ). A history of $\geq 3$ back accidents was associated with a distinctly increased risk of dark nucleus pulposus in discs L3/L4 and L4/L5. A history of frequent physical exercise showed a protective effect on L5/S1, but not on the other 2 discs. The other covariates were not statistically significantly associated with dark nuclei pulposi.

\section{Posterior disc bulge}

The prevalence of posterior disc bulges increased in the caudal direction, being highest at each level among the

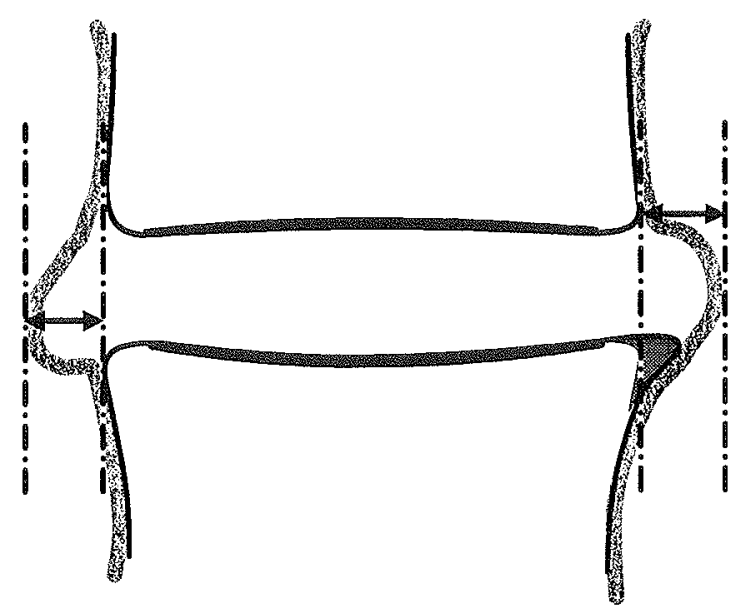

Figure 2. Dlagram of the measurement of the disc bulge. The dotted line connects the outer edges of adjacent vertebrae. Osteophytes have been excluded. The maximal distance (arrows) from the line to the disc margin, including the longitudinal ligament and the dura, has been measured.

carpenters. The carpenters had the highest prevalence at L4/L5 (figure 4).

In the overall analysis of the lumbar spine, no significant relation between occupation and posterior disc bulges was found ( $\chi^{2}$ test, $P=0.15$ ), but a history of back accidents was significantly related to an increased risk of posterior disc bulges ( $\chi^{2}$ test, $\mathrm{P}=0.02$ ).

In the disc-level-specific analyses, the carpenters showed an increased risk of posterior disc bulge at L3/ L4, but the relationship lost its significance as history of back accidents was added to the model (table 3 ). A history of back accidents was associated with an increased risk of disc degeneration at L3/L4 and L4/L5, but the relationship between back accidents and posterior bulge was significant only for L3/L4, as adjusted for confounders.

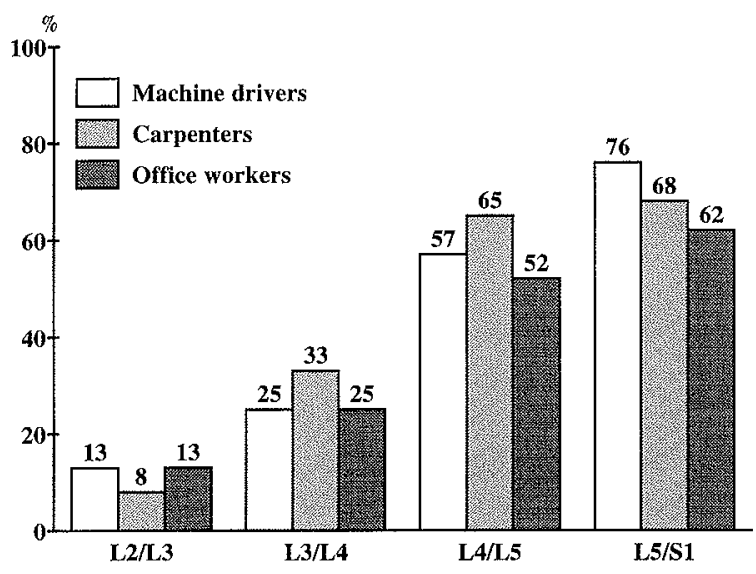

Figure 3. Prevalence of dark nucleus pulposus in discs $L 2 / L 3-L 5 / S 1$ among the occupational groups.

Scand J Work Environ Health 1998, vol 24, no 5 
Table 2. Effect of occupation and history of back accidents on the prevalence of dark nucleus pulposus. (OR = odds ratio, $95 \% \mathrm{Cl}=95 \%$ confidence interval)

\begin{tabular}{|c|c|c|c|c|c|c|}
\hline \multirow[t]{2}{*}{ Disc level } & \multicolumn{2}{|c|}{ Unadjusted } & \multicolumn{2}{|c|}{ Mutually adjusted } & \multicolumn{2}{|c|}{ Adjusted for confounders ${ }^{a}$} \\
\hline & Crude OR & $95 \% \mathrm{Cl}$ & OR & $95 \% \mathrm{Cl}$ & OR & $95 \% \mathrm{Cl}$ \\
\hline \multicolumn{7}{|l|}{$\mathrm{L} 3 / \mathrm{L} 4$} \\
\hline \multicolumn{7}{|l|}{ Occupation } \\
\hline Office workers & 1.0 & & 1.0 & & 1.0 & \\
\hline Machine drivers & 0.9 & $0.3-2.4$ & 0.7 & $0.3-1.9$ & 0.8 & $0.3-2.3$ \\
\hline Carpenters & 1.5 & $0.6-3.7$ & 1.1 & $0.4-2.8$ & 1.4 & $0.5-4.0$ \\
\hline \multicolumn{7}{|c|}{ History of back accidents } \\
\hline None & 1.0 & & 1.0 & & 1.0 & \\
\hline $1-2$ & 1.1 & $0.4-2.8$ & 1.1 & $0.4-2.7$ & 0.9 & $0.3-2.4$ \\
\hline$\geq 3$ & 5.2 & $1.7-16.1$ & 5.7 & $1.9-17.2$ & 5.7 & $1.7-18.7$ \\
\hline \multicolumn{7}{|l|}{ L4/L5 } \\
\hline \multicolumn{7}{|l|}{ Occupation } \\
\hline Office workers & 1.0 & & 1.0 & & 1.0 & \\
\hline Machine drivers & 1.2 & $0.5-2.8$ & 1.0 & $0.4-2.2$ & 1.0 & $0.4-2.4$ \\
\hline Carpenters & 1.7 & $0.7-3.9$ & 1.2 & $0.5-2.9$ & 1.3 & $0.5-3.2$ \\
\hline \multicolumn{7}{|c|}{ History of back accidents } \\
\hline None & 1.0 & & 1.0 & & 1.0 & \\
\hline $1-2$ & 1.4 & $0.6-3.2$ & 1.3 & $0.6-3.0$ & 1.3 & $0.5-3.1$ \\
\hline$\geq 3$ & 5.4 & $1.3-25.0$ & 5.0 & $1.3-18.9$ & 5.3 & $1.3-21.1$ \\
\hline \multicolumn{7}{|l|}{ L5/ S1 } \\
\hline \multicolumn{7}{|l|}{ Occupation } \\
\hline Office workers & 1.0 & & 1.0 & & 1.0 & \\
\hline Machine drivers & 1.8 & $0.7-4.9$ & 2.0 & $0.8-5.1$ & 2.3 & $0.8-6.4$ \\
\hline Carpenters & 1.2 & $0.5-3.2$ & 1.5 & $0.6-3.7$ & 0.9 & $0.3-2.7$ \\
\hline \multicolumn{7}{|c|}{ History of back accidents } \\
\hline None & 1.0 & & 1.0 & & 1.0 & \\
\hline $1-2$ & 0.8 & $0.3-2.1$ & 0.6 & $0.2-1.6$ & 0.9 & $0.3-2.5$ \\
\hline$\geq 3$ & 1.6 & $0.4-6.6$ & 1.1 & $0.3-4.2$ & 1.9 & $0.4-8.1$ \\
\hline
\end{tabular}

adjusted for height, history of overweight, smoking, physical exercise, and car driving.

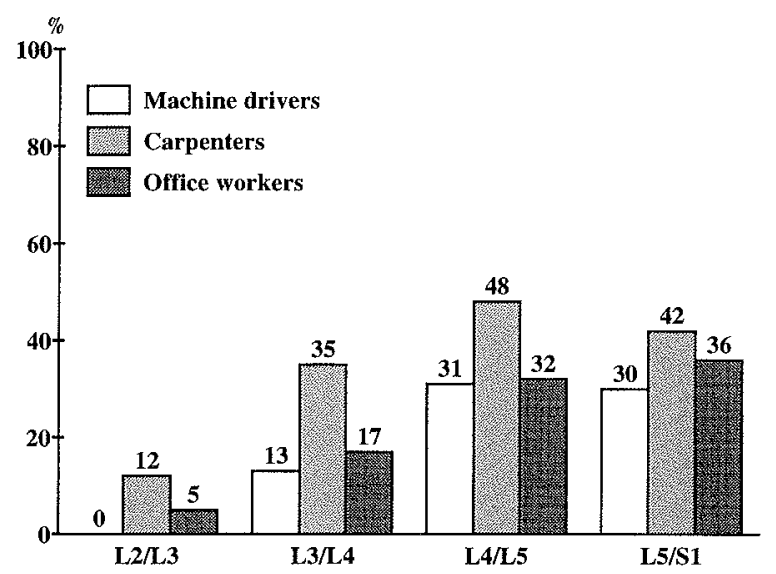

Figure 4. Prevalence of posterior bulge in discs $L 2 / L 3-L 5 / S 1$ among the occupational groups.

\section{Anterior disc bulge}

The prevalence of anterior disc bulge was fairly evenly distributed across the whole lumbar spine, and the machine drivers had the highest prevalences (figure 5). In the overall analysis of the lumbar spine, occupation $\left(\chi^{2}\right.$ test, $\mathrm{P}=0.004)$ and history of back accidents ( $\chi^{2}$ test, $\mathrm{P}=0.01$ ) were statistically significantly related to anterior disc bulges.
In the disc-level-specific analyses the machine drivers showed a higher risk of anterior disk bulge than the office workers at each level. At L3/L4 the relative risk lost its significance when adjusted for other covariates (table 4). For the carpenters the relationship was not statistically significant. A history of back accidents was associated with an increased risk at L3/L4 and L4/L5, although the risk did not reach statistical significance in the multivariate analysis. A history of car driving was associated with an increased risk at L3/L4 and L4/L5.

\section{Discussion}

In this study, occupational loading was found to be related to the presence of disc degeneration. The prevalence of different types of disc bulges varied in relation to occupation and disc level. A decreased signal intensity of the nucleus pulposus was not related to occupational load.

The signal intensity of a disc is associated with its water content and the degree of degeneration (19-20). We estimated the intensity in the region of the disc with the highest water content, the nucleus pulposus. As another indicator of degeneration, we used disc bulging 
Table 3. Effect of occupation and history of back accidents on the prevalence of discs with posterior bulge. (OR $=$ odds ratios, $95 \% \mathrm{Cl}$ $=95 \%$ confidence intervals)

\begin{tabular}{|c|c|c|c|c|c|c|}
\hline \multirow[t]{2}{*}{ Disc level } & \multicolumn{2}{|c|}{ Unadjusted } & \multicolumn{2}{|c|}{ Mutually adjusted } & \multicolumn{2}{|c|}{ Adjusted for confounders } \\
\hline & Crude OR & $95 \% \mathrm{Cl}$ & OR & $95 \% \mathrm{Cl}$ & $\mathrm{OR}$ & $95 \% \mathrm{Cl}$ \\
\hline \multicolumn{7}{|l|}{$\lfloor 3 /\llcorner 4$} \\
\hline \multicolumn{7}{|l|}{ Occupation } \\
\hline Office workers & 1.0 & & 1.0 & & 1.0 & \\
\hline Machine drivers & 0.7 & $0.2-2.4$ & 0.5 & $0.1-1.7$ & 0.6 & $0.1-2.1$ \\
\hline Carpenters & 2.7 & $1.0-7.3$ & 1.9 & $0.7-5.1$ & 2.2 & $0.7-6.6$ \\
\hline \multicolumn{7}{|c|}{ History of back accidents } \\
\hline None & 1.0 & & 1.0 & & 1.0 & \\
\hline $1-2$ & 1.3 & $0.4-3.6$ & 1.2 & $0.4-3.3$ & 1.2 & $0.4-3.4$ \\
\hline$\geq 3$ & 6.6 & $2.1-21.1$ & 5.4 & $1.7-17.0$ & 6.6 & $1.9-22.9$ \\
\hline \multicolumn{7}{|l|}{ L4/L5 } \\
\hline \multicolumn{7}{|l|}{ Occupation } \\
\hline Office workers & 1.0 & & 1.0 & & 1.0 & \\
\hline Machine drivers & 0.9 & $0.4-2.3$ & 0.7 & $0.3-1.8$ & 0.6 & $0.2-1.5$ \\
\hline Carpenters & 1.9 & $0.8-4.6$ & 1.4 & $0.6-3.4$ & 1.0 & $0.4-2.6$ \\
\hline \multicolumn{7}{|c|}{ History of back accidents } \\
\hline None & 1.0 & & 1.0 & & 1.0 & \\
\hline $1-2$ & 1.6 & $0.7-3.6$ & 1.6 & $0.7-3.5$ & 1.9 & $0.8-4.5$ \\
\hline$\geq 3$ & 3.1 & $1.0-9.6$ & 2.6 & $0.8-7.7$ & 2.4 & $0.7-7.7$ \\
\hline \multicolumn{7}{|l|}{$\mathrm{L} 5 / \mathrm{S} 1$} \\
\hline \multicolumn{7}{|l|}{ Occupation } \\
\hline Office workers & 1.0 & & 1.0 & & 1.0 & \\
\hline Machine drivers & 0.7 & $0.3-1.8$ & 0.8 & $0.3-1.9$ & 0.9 & $0.3-2.2$ \\
\hline Carpenters & 1.2 & $0.5-3.0$ & 1.4 & $0.6-3.3$ & 1.5 & $0.6-3.9$ \\
\hline \multicolumn{7}{|c|}{ History of back accidents } \\
\hline None & 1.0 & & 1.0 & & 1.0 & \\
\hline $1-2$ & 0.9 & $0.3-2.1$ & 0.8 & $0.3-1.9$ & 0.9 & $0.3-2.3$ \\
\hline$\geq 3$ & 0.9 & $0.3-2.8$ & 0.7 & $0.2-2.1$ & 0.8 & $0.2-2.8$ \\
\hline
\end{tabular}

adjusted for height, history of overweight, smoking, physical exercise, and car driving.

as measured in the middle line in the sagittal plane. Degenerated discs have radial tears (27). Discs with bulging of $\geq 2.5 \mathrm{~mm}$ beyond the posterior border of the vertebra are shown to be likely to have a radial tear (22). We chose a bulge of $\geq 3.2 \mathrm{~mm}$ as a sign of degeneration. In addition 2 pixels $(3.2 \mathrm{~mm})$ was considered the smallest size to be reliably measured.

In some cases it was difficult to determine the measuring points due to the variation in the shape of the posterior or anterior border of the vertebral body. In addition osteophytes can affect the validity of the assessment of disc bulges, although in many cases the osteophyte can be clearly demarcated from the cancellous bone by a different signal intensity. The relative importance of the size of a disc bulge may be different at different disc levels. The large pixel size did not, however, allow a more-detailed analysis in this study.

Image quality, affected by subject- and equipmentrelated factors, may create some problems for the evaluation of discs. Signal intensity of the nucleus pulposus is affected by patient size, distance from the surface coil, CSF flow, and the diurnal variation of the water content of the discs (28). CSF flow is assumed to have a minor effect (29). The recovery of the water content of a disc after a period of standing is known to be fairly fast in bed rest (30). The subjects lay recumbent in the imager

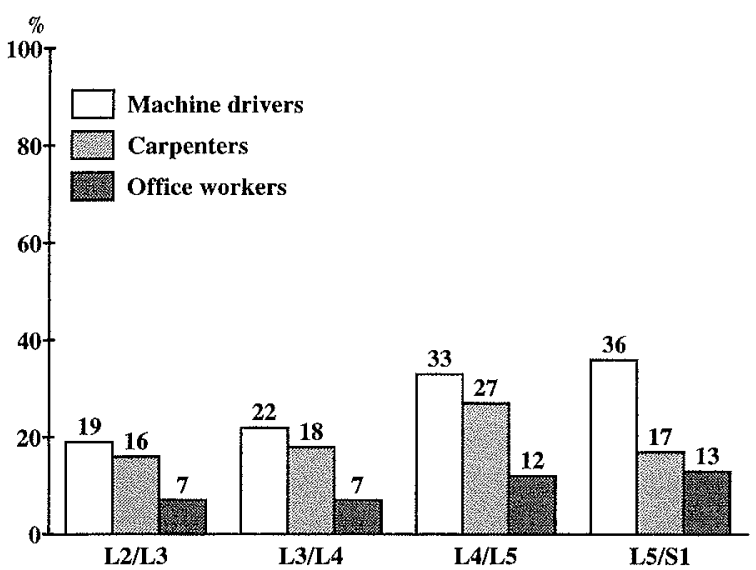

Figure 5. Prevalence of anterior bulges in discs $L 2 / L 3-L 5 / S 1$ among the occupational groups.

at least 20 minutes before the imaging was started; this procedure was expected to assure an almost full recovery of the water content of the discs. Suitability of the CSF as a signal intensity reference has been documented $(24-25)$.

The repeatability of the signal intensity assessment and of the measurement of the anterior and posterior bulges varied from excellent to fair. At L5/S1 the repeatability was poorer than at the other levels, and most of 
Table 4. Effect of occupation, history of back accidents, and car driving on the prevalence of discs with dark anterior bulge. (OR $=0$ odds ratios, $95 \% \mathrm{Cl}=95 \%$ confidence intervals)

\begin{tabular}{|c|c|c|c|c|c|c|}
\hline \multirow[t]{2}{*}{ Disc level } & \multicolumn{2}{|c|}{ Unadjusted } & \multicolumn{2}{|c|}{ Mutually adjusted } & \multicolumn{2}{|c|}{ Adjusted for confoundersa } \\
\hline & Crude OR & $95 \% \mathrm{Cl}$ & $\mathrm{OR}$ & $95 \% \mathrm{Cl}$ & $\mathrm{OR}$ & $95 \% \mathrm{Cl}$ \\
\hline \multicolumn{7}{|l|}{ L3/L4 } \\
\hline \multicolumn{7}{|l|}{ Occupation } \\
\hline Office workers & 1.0 & & 1.0 & & 1.0 & \\
\hline Machine drivers & 3.8 & $1.0-15.6$ & 2.9 & $0.7-10.6$ & 3.0 & $0.7-12.5$ \\
\hline Carpenters & 3.0 & $0.7-12.8$ & 1.9 & $0.5-7.7$ & 2.2 & $0.5-9.5$ \\
\hline \multicolumn{7}{|c|}{ History of back accidents } \\
\hline None & 1.0 & & 1.0 & & 1.0 & \\
\hline $1-2$ & 0.7 & $0.1-2.7$ & 0.6 & $0.1-2.1$ & 0.6 & $0.1-2.4$ \\
\hline$\geq 3$ & 3.9 & $1.1-13.6$ & 3.3 & $1.0-11.4$ & 2.6 & $0.7-9.9$ \\
\hline \multicolumn{7}{|l|}{ History of car driving } \\
\hline$<15000 \mathrm{~km} /$ year & 1.0 & & 1.0 & & 1.0 & \\
\hline$\geq 15000 \mathrm{~km} /$ year & 3.3 & $1.2-8.8$ & 2.9 & $1.1-7.5$ & 3.1 & $1.1-8.9$ \\
\hline \multicolumn{7}{|l|}{$\mathrm{L} 4 / \mathrm{L} 5$} \\
\hline \multicolumn{7}{|l|}{ Occupation } \\
\hline Office workers & 1.0 & & 1.0 & & 1.0 & \\
\hline Machine drivers & 3.6 & $1.2-11.1$ & 2.9 & $1.0-8.3$ & 3.3 & $1.0-10.1$ \\
\hline Carpenters & 2.7 & $0.9-8.5$ & 1.8 & $0.6-5.6$ & 1.6 & $0.5-5.4$ \\
\hline \multicolumn{7}{|c|}{ History of back accidents } \\
\hline None & 1.0 & & 1.0 & & 1.0 & \\
\hline $1-2$ & 1.2 & $0.4-3.4$ & 1.0 & $0.4-2.8$ & 1.3 & $0.4-3.7$ \\
\hline$\geq 3$ & 3.1 & $0.9-9.8$ & 2.4 & $0.7-7.3$ & 2.7 & $0.7-9.7$ \\
\hline \multicolumn{7}{|l|}{ History of car driving } \\
\hline$<15000 \mathrm{~km} /$ year & 1.0 & & 1.0 & & 1.0 & \\
\hline$\geq 15000 \mathrm{~km} /$ year & 2.3 & $1.0-5.4$ & 1.9 & $0.8-4.4$ & 2.1 & $0.8-5.4$ \\
\hline \multicolumn{7}{|l|}{ L5/S1 } \\
\hline \multicolumn{7}{|l|}{ Occupation } \\
\hline Office workers & 1.0 & & 1.0 & & 1.0 & \\
\hline Machine drivers & 3.8 & $1.2-11.8$ & 3.1 & $1.1-9.0$ & 4.2 & $1.2-14.1$ \\
\hline Carpenters & 1.4 & $0.4-4.8$ & 1.1 & $0.3-3.7$ & 1.1 & $0.3-4.0$ \\
\hline \multicolumn{7}{|c|}{ History of back accidents } \\
\hline None & 1.0 & & 1.0 & & 1.0 & \\
\hline $1-2$ & 3.2 & $1.2-8.5$ & 2.9 & $1.1-7.5$ & 3.0 & $1.1-8.5$ \\
\hline$\geq 3$ & 1.0 & $0.2-4.7$ & 1.0 & $0.2-4.2$ & 0.9 & $0.1-4.7$ \\
\hline \multicolumn{7}{|l|}{ History of car driving } \\
\hline$<15000 \mathrm{~km} /$ year & 1.0 & & 1.0 & & 1.0 & \\
\hline$\geq 15000 \mathrm{~km} /$ year & 0.9 & $0.3-2.4$ & 1.1 & $0.4-2.8$ & 1.6 & $0.5-4.7$ \\
\hline
\end{tabular}

a Adjusted for height, history of overweight, smoking, and physical exercise.

the missing observations were at this level. Therefore the results for L5/S1 may be somewhat less reliable. The posterior border of the disc was more distinct than the anterior border in most cases because of a shorter distance from the coil. Thus better repeatability in the assessment of the posterior bulges could be expected.

Trauma to the annulus fibrosus can initiate a progressive degenerative process in the disc, as suggested by an animal study (31). In a cross-sectional study the time sequence between the development of disc degeneration and previous accidental back injuries remains obscure. Thus it is not possible to draw definite conclusions about the role of back accidents as initiators or promoters of disc degeneration. Developing disc degeneration may also predispose the back to painful injuries. The association between accidental back injuries and disc degeneration should be studied with a prospective design. As the measure of back trauma, we used the number of self-reported back accidents. Although self-reporting is not a very reliable means of obtaining retrospective data because of recall error (32), it was the only possibility. The limit of 2 weeks' absence from work was chosen to improve reliability because such accidents are obviously more serious and will be remembered better. However, events associated with back pain may have been classified as back accidents even if no true trauma occurred.

In our study, posterior bulges were related to dynamic physical work in which compressive and shear forces act on the lumbar spine. The association reached statistical significance only at one disc level, although there was a consistent relationship across the spine. The risk of posterior bulges was decreased in the multivariate modeling at all disc levels as the history of back accidents was added to the model. A high risk of accident is an essential feature of a carpenter's work and, accordingly, explains part of the association between posterior bulge and occupation. Our results concerning the association of heavy physical work or repeated injuries with disc degeneration are in accordance with the results of previous studies $(2-3,15)$. 
Machine driving and car driving involve whole-body vibration, which has been suggested to affect the metabolism of the discs $(6,33)$, while sudden shocks act on the discs and adjacent vertebrae through compressive forces. As a result, degenerative changes can develop. Constrained, forward flexed, and twisted postures of the trunk are common in machine driving work. The mechanism by which anterior bulges develop is not clear, however.

In this study we kept the different signs of disc degeneration separate in the analysis and used no general score, unlike some other investigators $(8,10)$. Had we used a general score, no occupational differences would have been found because dark nucleus pulposus, unrelated to occupation, was the most prevalent sign of degeneration, and disc bulge occurred in most cases concomitantly with dark nucleus pulposus.

The prevalence of decreased signal intensity of the nucleus pulposus and posterior bulge of the disc varied between the disc levels and increased towards the lower levels. The prevalence of anterior disc bulge was more similar at all the disc levels. The differences in the prevalence of the signs of disc degeneration between the disc levels may be caused by differences in physical loading. Vascular etiology has also been suggested to explain such differences (34).

The association between a history of back accidents and disc degeneration was statistically significant for L3/ L4 and L4/L5, but not for L5/S1. Disc degeneration was the most advanced at L5/S1, as measured by decreased signal intensity, depicting the overall cumulative effect of various risk factors. This phenomenon may be one reason why the effect of accidents was not detected.

The most prevalent sign of disc degeneration among the carpenters was posterior bulge, and among the machine drivers it was anterior bulge. Sedentary and heavy physical work has been found to be related to different degenerative changes in an autopsy study (3), but anterior disc bulges have not been used earlier as outcomes in epidemiologic studies.

The subject size and position in the imager may affect the size of disc bulge. The machine drivers were taller, on the average, than the men in the other 2 groups, but height was not significantly associated with disc degeneration in the multivariate modeling. Eventual differences in the degree of lumbar lordosis between occupational groups could also explain the differences, but lordosis was not measured in the neutral position.

Evidence has been found for a strengthening effect of heavy manual work on the spine (16), and inactivity has been suggested to play a role in the etiopathogenesis of degenerative changes in the musculoskeletal system (35). We did not find evidence to support such effects. Neither do our results support the hypothesis suggested in previous studies that sedentary work (7), smoking
(8-9), overweight $(10-11)$, or heavy leisure-time physical exercise (5) would enhance disc degeneration. The size of this study, however, was small, and thus the statistical power was too low to investigate the effect of many explanatory variables. The healthy worker effect also diminishes possibilities to detect associations between occupation and disc degeneration since people who develop back problems may select a less strenuous occupation.

For car driving, physical exercise, and overweight we used variables in which the history of exposure was accumulated based on current questionnaire data and on data from 4 and 7 years in retrospect. The consideration of cumulative exposure is feasible in reference to disc degeneration, which is a slowly developing process. The use of data from 3 questionnaires also makes the data collected more reliable than those of a pure cross-sectional study, thus reducing recall error.

Our study adds to the evidence that environmental factors, such as occupational load, play a role in the development of disc degeneration of the lumbar spine. A history of back accidents and car driving was associated with an increased risk of disc degeneration, but conclusions about a causal relationship cannot be drawn due to the cross-sectional setting of the study. Anterior and posterior disc bulges seem to be related to different types of physical loads.

\section{Acknowledgments}

This work was financially supported by the Finnish Work Environment Fund, the LEL Employment Pension Fund, and the Instrumentarium Scientific Foundation.

We thank Rami Martikainen and Petri Toivonen for assisting in the data analysis and Kai Ceder, Tiina Karjalainen, Mika Koivisto, Pentti Pölönen, and Raija Vainonen for interviewing and imaging the subjects.

\section{References}

1. Lawrence IS. Rheumatism in coal miners, part III: occupational factors. Br J Ind Med 1955;12:249—61.

2. Riihimäki $H$, Mattsson $T$, Zitting $A$, Wickström $G$, Hänninen $\mathrm{K}$, Waris P. Radiographically detectable degenerative changes of the lumbar spine among concrete reinforcement workers and house painters. Spine 1990;15:114-9.

3. Videman T, Nurminen M, Troup JDG. Lumbar spinal pathology in cadaveric material in relation to history of back pain, occupation, and physical loading. Spine 1990;15:728-40.

4. Troup JDG. Relation of lumbar spine disorders to heavy manual work and lifting. Lancet 1965:1:857-61.

5. Swärd L, Hellström M, Jacobsson B, Nyman R, Peterson L. Disc degeneration and associated abnormalities of the spine in 
elite gymnasts: a magnetic resonance imaging study. Spine 1991;16:437-43.

6. Dupuis $\mathrm{H}$, Zerlett $\mathrm{G}$. Whole-body vibration and disorders of the spine. Int Arch Occup Environ Health 1987;59:323-36.

7. Evans W, Jobe W, Seibert C. A cross-sectional prevalence study of lumbar disc degeneration in a working population. Spine 1989;14:60-4.

8. Battié MC, Viđeman T, Gill K, Moneta GB, Nyman R, Kaprio J, et al. Smoking and lumbar intervertebral disc degeneration: an MRI study of identical twins. Spine 1991;16:101521.

9. Holm S, Nachemson A. Nutrition of the intervertebral disc: acute effects of cigarette smoking: an experimental animal study. Ups J Med Sci 1988;93:91-9.

10. Parkkola R, Kormano M. Lumbar disc and back muscle degeneration on MRI: correlation to age and body mass. J Spinal Disord 1992;5:86-92.

11. Symmons DPM, van Hermert AM, Vandenbroucke JP, Valkenburg HA. A longitudinal study of back pain and radiological changes in the lumbar spines of middle aged women, II: radiographic findings. Ann Rheum Dis 1991;50:162—6.

12. Battié MC, Videman T, Gibbons LE, Fisher LD, Manninen H, Gill K. Determinants of lumbar disc degeneration: a study relating lifetime exposures and magnetic resonance imaging findings in identical twins. Spine 1995;20:2601-12.

13. Biering-Sørensen F, Hansen FR, Schroll M, Runeborg O. The relation of spinal X-ray to low-back pain and physical activity among 60-year-old men and women. Spine 1985;10:445-51.

14. Hult L. A study of the frequency and causes of the stiff neckbrachialgia and lumbago-sciatica syndromes, as well as observations on certain signs and symptoms from the dorsal spine and the joints of the extremities in industrial and forest workers: the Munkfors Investigation. Acta Orthop Scand 1954: suppl 16:1-76.

15. Lawrence JS. Disc degeneration: its frequency and relationship to symptoms. Ann Rheum Dis 1969;28:121-37.

16. Porter RW. Does hard work prevent disc protrusion? Clin Biomech 1987;2:196-8.

17. Modic MT, Pavlicek W, Weinstein MA, Boumphrey F, Ngo F, Hardy R, et al. Magnetic resonance imaging of intervertebral disk disease: clinical and pulse sequence considerations. Radiology 1984;152:103-11.

18. Schiebler ML, Camerino VJ, Fallon MD, Zlatkin MB, Grenier N, Kressel HY. In vivo and ex vivo magnetic resonance imaging evaluation of early disc degeneration with histopathologic correlation. Spine 1991;16:635-40.

19. Tertti M, Paajanen H, Laato M, Aho H, Komu M, Kormano $M$. Disc degeneration in magnetic resonance imaging: a comparative biochemical, histologic and radiologic study in cadaver spines. Spine 1991;16:629-34.

20. Wagner M, Sether LA, Yu S, Ho PSP, Haughton VM. Age changes in the lumbar intervertebral disc studied with magnetic resonance and cryomicrotomy. Clin Anat 1988;1:93-
103.

21. Yu S, Haughton VM, Sether LA, Ho K-C, Wagner M. Criteria for classifying normal and degenerated lumbar intervertebral disks. Radiology 1989;170:523-6.

22. Yu S, Haughton VM, Sether LA, Wagner M. Anulus fibrosus in bulging intervertebral disks. Radiology 1988;169:761-3.

23. Buirski G. Magnetic resonance signal patterns of lumbar discs in patients with low back pain: a prospective study with discographic correlation. Spine 1992;17:1199-204.

24. Luoma EK, Raininko R, Nummi PJ, Luukkonen R, Manninen HI, Rihimäki HA. Suitability of cerebrospinal fluid as a signal intensity reference on MRI: evaluation of signal-intensity variations in the lumbosacral dural sac. Neuroradiology 1997;39:728-32.

25. Luoma K, Raininko R, Nummi P, Luukkonen R. Is the signal intensity of cerebrospinal fluid constant? Intensity measurements with high and low field magnetic resonance imagers. Magn Reson Imaging 1993;11:549-55.

26. Aresti A. Analyzing repeated categorical response data. In: Categorical data analysis. New York (NY): John Wiley \& Sons, 1990:386-417.

27. Hirsch C, Schajowicz F. Studies on structural changes in the lumbar annulus fibrosus. Acta Orthop Scand 1952;22:184231.

28. Paajanen H, Lehto I, Alanen A, Erkintalo M, Komu M. Diurnal fluid changes of lumbar discs measured indirectly by magnetic resonance imaging. J Orthop Res 1994;12:509-14.

29. Greitz D, Franck A, Nordell B. On the pulsatile nature of intracranial and spinal CSF-circulation demonstrated by MR Imaging. Acta Radiol 1993;34:321-8.

30. Althoff I, Brinkmann IAP, Frobin W, Sandover J, Burton K. An improved method of stature measurement for quantitative determination of spinal loading: application to sitting postures and whole body vibration. Spine 1992;17:682-93.

31. Kääpä E, Han X, Holm S, Peltonen J, Takala T, Vanharanta H. Collagen synthesis and types I, III, IV and VI collagens in a animal model of disc degeneration. Spine 1995;20:59-67.

32. Riihimäki H, Viikari-Juntura E, Moneta G, Kuha J, Videman $\mathrm{T}$, Tola $\mathrm{S}$. Incidence of sciatic pain among men in machine operating, dynamic physical work, and sedentary work: a three-year follow-up. Spine 1994;19:138-42.

33. Hansson T, Holm S. Clinical implications of vibration-induced changes in the lumbar spine. Orthop Clin North Am 1991;22:247-53.

34. Kauppila LI, Penttilä A, Karhunen PJ, Lalu K, Hannikainen P. Lumbar disc degeneration and atherosclerosis of the abdominal aorta. Spine 1994;19:923-9.

35. Troup JDG, Videman T. Inactivity and the aetiopathogenesis of musculoskeletal disorders: new concepts and hypotheses. Clin Biomech 1989;4:173-8.

Received for publication: 23 December 1997 